\title{
Devising urban ecosystem-based adaptation (EbA) projects with developing nations: A case study of Port Vila, Vanuatu
}

\author{
Maibritt Pedersen Zari ${ }^{a, *}$, Paul M. Blaschke ${ }^{\text {, }, ~}$, Bethanna Jackson ${ }^{b}$, Aimee Komugabe-Dixson ${ }^{c}$, \\ Chris Livesey $^{\mathrm{d}}$, David I. Loubser ${ }^{\mathrm{e}}$, Carles Martinez-Almoyna Gual ${ }^{\mathrm{a}}$, Deborah Maxwell ${ }^{\mathrm{b}}$, \\ Amin Rastandeh $^{\mathrm{a}}$, James Renwick ${ }^{\mathrm{b}}$, Sean Weaver ${ }^{\mathrm{f}}$, Kelli M. Archie ${ }^{\mathrm{b}}$ \\ ${ }^{\text {a }}$ School of Architecture, Victoria University of Wellington, New Zealand \\ ${ }^{\mathrm{b}}$ School of Geography, Environment, and Earth Sciences, Victoria University of Wellington, New Zealand \\ ${ }^{\mathrm{c}}$ Fisheries New Zealand, Ministry for Primary Industries, New Zealand \\ ${ }^{\mathrm{d}}$ Chris Livesey Consulting, Wellington, New Zealand \\ ${ }^{\mathrm{e}}$ Ecosystems Services Ltd., Wellington, New Zealand \\ ${ }^{\mathrm{f}}$ Ekos, Christchurch, New Zealand \\ ${ }^{g}$ Blaschke and Rutherford Environmental Consultants, Wellington, New Zealand
}

\section{A R T I C L E I N F O}

\section{Keywords:}

Ecosystem services

Urban biodiversity

Nature-based solutions

Socio-ecological systems

Climate change

\begin{abstract}
A B S T R A C T
As the linked impacts of climate change and degradation of ecosystems continue to be felt, particularly in developing countries, it is vital that methods for development that concurrently address adaptation to climate change, rapid urbanisation, and ecosystem degradation be explored. Further development of approaches which are participatory and embedded in an understanding of the importance of symbiotic relationships between sociocultural and ecological systems is particularly important. Ecosystem-based adaptation (EbA) is one such method that is gaining recognition and momentum in areas where developing nations face converging pressures and drivers of change. EbA methodologies to date, are often ill-defined in an urban context and lack consideration of future social and ecological scenarios however. In response, this paper describes a methodology for developing urban EbA projects in a small island developing nation context. The methodology was developed and applied by a multi-disciplinary team working under the auspices of the Secretariat of the Pacific Regional Environment Programme (SPREP). The application of this methodology in Port Vila, Vanuatu indicated: i) the needs of local people must be at the forefront of project planning, requiring a participatory design process; ii) EbA solutions development must be multidisciplinary and iterative; iii) appropriate quantitative and qualitative data is vital as a basis for EbA project development, requiring adequate time for data gathering; iv) urban and coastal EbA projects must be developed holistically, recognising socio-ecological systems that extend beyond the urban area itself; v) the complex overlapping landscape of governmental and international aid financed projects must inform the development of new EbA projects; vi) potential monetary and non-monetary benefits, costs and risks across multiple factors must be carefully assessed in EbA project development; and vii) project implementation requires ongoing engagement and a readiness to adapt to on-the-ground realities.
\end{abstract}

\section{Introduction}

Humanity faces a convergence of ecological and climatic changes that are beginning to profoundly affect civilisation, particularly people already in poverty (Hallegatte et al., 2015; Montanarella et al., 2018; Rockstrom et al., 2009). More than half of the growing human population is now urbanised, and urbanisation rates are increasing particularly in developing nations (Eigenbrod et al., 2011). The problem of how to remediate urban areas so they create ecological and societal health, while becoming more resilient to increasing impacts must be addressed (Pedersen Zari, 2018). Because the impacts of both climate change and rapid ecological change are felt acutely in developing nations, strategies to increase resilience while increasing human wellbeing are urgently needed (Wise et al., 2014).

One way to reduce the negative social and ecological impacts of climate change and rapid unplanned development may be to employ

\footnotetext{
* Corresponding author. PO Box 600, CBD, Wellington, 6011, New Zealand.

E-mail address: maibritt.pedersen@vuw.ac.nz (M. Pedersen Zari).
} 
ecosystem-based adaptation (EbA) approaches, so that development supports ecosystem services, and therefore increases human wellbeing (Geneletti and Zardo, 2016; T. Hills, T. J. B. Carruthers, S. Chape, \& P. Donohoe, 2013, McPhearson et al., 2018). Despite growing investigation and employment of EbA and nature-based solutions in general, particularly in European Union funded projects (Keestra et al., 2018; Cohen-Shacham et al., 2016), EbA can be ill-defined, and often lacks consideration of future scenarios of change that address interlinked social and ecological contexts (Brink et al., 2016). Furthermore, EbA projects often target the support or regeneration of ecosystems outside of urban areas, meaning guidance on processes to devise urban EbA projects is lacking. An EbA approach in urban areas seeks to integrate urban ecologies more effectively with naturally occurring ecosystems by working towards linkages between living and built urban environments and their surrounding peri-urban areas. The aim of this research then is threefold: (1) to propose a methodology for devising EbA projects in a developing nation urban context that considers social issues and future scenarios; (2) explore how the proposed methodology can be applied to real world urban situations; and (3) report briefly on results from the case study in order to propose refinement and development of the EbA process.

\subsection{Ecosystem-based adaptation: definition and importance}

EbA leverages an understanding of relationships between ecosystems, the ways people live, and the wellbeing and resilience of communities, in order to achieve maximum benefit for people. It aims to do this by working with rather than against nature for adaptation to the impacts of climate change (Pedersen Zari et al., 2017). Fundamentally, EbA is the practice of strengthening biodiversity and ecosystems to increase people's ability to adapt to the impacts of climate change (Munang et al., 2013). It draws upon knowledge of ecosystem services, which are the benefits people get from ecosystems (Potschin et al., 2016). EbA is based on the premise that if ecosystems are protected, remediated, or regenerated, this leads to healthier ecosystems, more ecosystem services, and therefore greater human wellbeing and resilience to the impacts of climate change. Several studies have demonstrated that in most cases, the costs of ecosystem conservation are far outweighed by the net benefits generated by healthy intact ecosystems (Turner and Daily, 2008).

EbA differs from typical sustainable development concepts in two key ways. Firstly, EbA can offer a more participatory approach, is often more flexible, and proposes more cost effective solutions to issues than some other 'hard', or engineered infrastructure adaptation strategies (Brink et al., 2016). EbA tends to result in less risk of conflicting outcomes in terms of mitigating the drivers of climate change, adapting to its impacts, and general protection of ecosystems and human wellbeing (Munang et al., 2013). For example, a typical response to coastal erosion, exacerbated by climate change, might be to erect a seawall. While this may solve the primary problem, it may be expensive, is often temporary, and does not address the drivers of coastal erosion such as vegetation loss. It may also cause maladaptive impacts in other locations such as increased erosion at different parts of the coast. Such a solution treats the symptoms of problems only, not their causes, meaning the initial drivers of the problem may continue to impact ecologies and people negatively. An EbA approach to the same problem might start with analysis of what the drivers of negative change are, and what the major impacts are in terms of ecosystem health, the provision of ecosystem services, and the wellbeing of people (Blaschke et al., 2017). By understanding these relationships, other 'soft' adaptation strategies can be devised that solve issues, reduce the causes of them, and often concurrently result in multiple benefits. In the aforementioned example of coastal erosion, an EbA approach might be to revegetate, protect, or restore native coastal ecologies. This reduces erosion, but also maintains culturally significant relationships between people and foreshore ecologies, and increases the amount of ecosystem services locally. This in turn increases communities' resilience to climate change as well as other environmental changes.

Secondly, EbA approaches to climate change often reveal through initial analysis of drivers of changes to ecosystems, that multiple interconnected drivers of change come from both climatic changes and also from the activities of local people (Mackey et al., 2017; McPhearson et al., 2018). In developing nations, these local human-caused drivers of change of ecosystems are often as big as, if not larger than, current climate-induced changes in ecosystems (Garschagen and Romero-Lankao, 2015). Therefore, EbA projects that seek to reduce the negative impacts of land cover change and consequently, ecosystem degradation, and that increase the quantity or quality of ecosystems services, often concurrently address other issues that result in a reduction in human wellbeing. This is one of the reasons that EbA has been adopted by a growing number of agencies and projects in the Pacific (Hills et al., 2013; Munang et al., 2013), where negative impacts of both climate change and rapid, often unplanned, urbanisation converge to create degradation of ecosystems and therefore reduced resilience (Connell, 2015). This is true of Port Vila, Vanuatu, which was selected as the research site in this study. Port Vila is one of the fastest growing urban centres in the region (McEvoy et al., 2017, page 12). This is at a time when resilience needs to be increased where possible to enable people to have higher potential to adapt to climate change (Bai et al., 2018).

\subsection{Geographical context}

\subsubsection{Vanuatu: a wider context}

Vanuatu is a small culturally diverse archipelago in the south-west Pacific Ocean (Fig. 1). It consists of over 80 islands set in a large oceanic zone of more than $660,000 \mathrm{~km}^{2}$ with a total landmass of only $12,200 \mathrm{~km}^{2}$. It is situated in one of the world's biodiversity hotspots and has a high rate of endemism (Mittermeier et al., 1998; Cincotta et al., 2000).

The 2017/8 World Risk Index ranking indicated that Vanuatu was the most at-risk of all countries assessed, based on its exposure to natural hazards (earthquakes, storms, floods, droughts and sea level rise) (Bündnis Entwicklung Hilft, 2017). Vanuatu also ranks very high (number 8) on the Global Climate Risk Index (Eckstein et al., 2017). Vanuatu's devastating experience of Tropical Cyclone Pam in 2015, followed immediately by a severe El Niño-Southern Oscillation drought which caused widespread food shortages, highlighted the vulnerability of the island nation (Magee et al., 2016). The Pacific Ecosystem-based Adaptation to Climate Change (PEBACC) Project responds to these vulnerability challenges by seeking to address climate change, and other issues related to rapid urbanisation in a developing nation context. The five-year Project, implemented by the Secretariat of the Pacific Regional Environment Programme (SPREP), and funded by the Bundesministerium für Umwelt, Naturschutz und nukleare Sicherheit of the German Federal Government, explores and develops EbA options for adapting to climate change in the Pacific region (SPREP, 2018a). The research reported on in this article is detailed in Blashchke et al. (2017), Pedersen Zari et al. (2017), and SPREP (2018b). It builds on an earlier PEBACC study that undertook a baseline ecosystem and socio-economic resilience analysis and mapping appraisal of the Port Vila Metropolitan area (McEvoy et al., 2017, Komugabe-Dixson et al., 2019).

Port Vila is the capital and largest city of Vanuatu, and is situated on the southern coast of Efate, the third largest island in Vanuatu. More than a quarter of Vanuatu's total population live in Metropolitan Port Vila. In 2016, the population of the city was approximately 75,000 (Table 1). Extremely high population growth rates are estimated to be up to $8 \%$ per annum. This is mostly due to internal migrants from other 


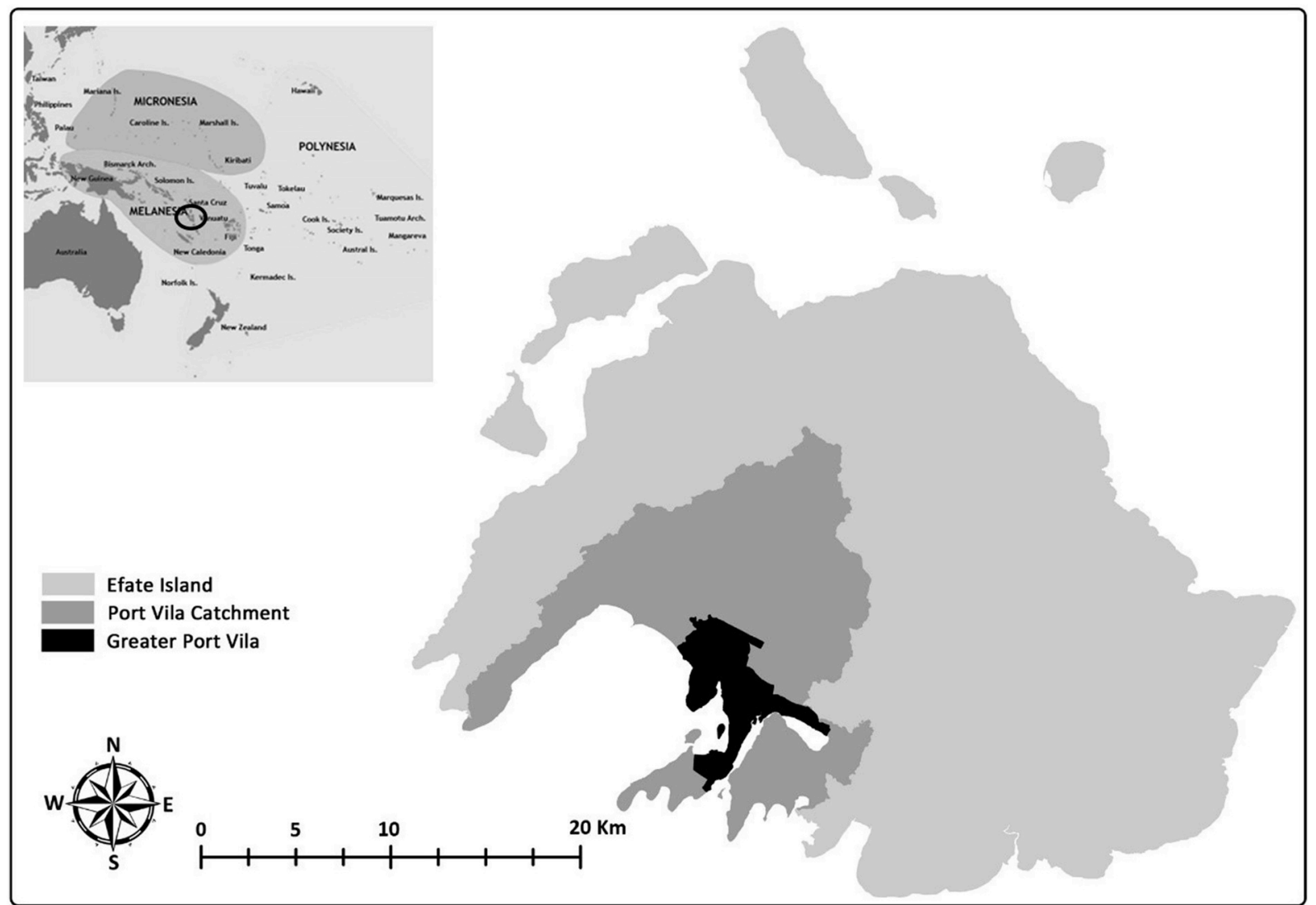

Fig. 1. Location of Vanuatu in the Pacific, and location of Port Vila on Efate Island (adapted from: Blaschke et al., 2017).

Table 1

Port Vila details.

\begin{tabular}{|c|c|c|c|c|c|}
\hline Population & Area & Topography & $\begin{array}{l}\text { Personal Income } \\
\text { (Atlas Method) }\end{array}$ & $\begin{array}{l}\text { Human } \\
\text { Develop-ment } \\
\text { Index }\end{array}$ & Climate Zone \\
\hline $\begin{array}{l}\text { Approx. 50,944 } \\
\text { (municipality, } \\
2016 \text { ) } \\
74,725 \text { (greater } \\
\text { metro, 2016) }\end{array}$ & $\begin{array}{l}24.3 \mathrm{~km}^{2} \text { (evenly split } \\
\text { between urban and peri- } \\
\text { urban areas) }\end{array}$ & $\begin{array}{l}\text { Located on the south-west coast of the small volcanic island of } \\
\text { Efate and the focal point of the north-south 'Y shaped' Vanuatu } \\
\text { archipelago. Next to several coral reefs and the Pacific Ocean. }\end{array}$ & \$US2,920 (2017) & $\begin{array}{l}0.603 \\
\text { (Vanuatu) }\end{array}$ & $\begin{array}{l}\text { Tropical } \\
\text { Rainforest Af }\end{array}$ \\
\hline
\end{tabular}

islands in Vanuatu (McEvoy et al., 2017). Apart from impacts imposed by anthropogenic development in the region, Port Vila is susceptible to a range of natural stressors including sea level rise, severe cyclones, rising temperatures as well as earthquakes and tsunamis (Birkman et al., 2014).

\subsection{Designing urban EbA projects}

The data gathered for this research included a spectrum of spatial and non-spatial information. The aim was to facilitate the process of creating baseline geospatial maps, examining states of ecosystems, preparing future climate change scenarios, and reviewing local use and understanding of ecosystem services. Following this, a process to identify potential EbA projects was devised and tested. Resulting potential projects were then refined, evaluated and tested further. Finally, a selection of five EbA projects were developed into full implementation plans. Collaborative interdisciplinary team and stakeholder workshops were an integral part of the approach. The following sections expand on how each part of this process was conceived and undertaken as summarised in Fig. 2. For readability, brief results of each step of the methodology found for the Port Vila context are reported upon in sequence rather than in a separate results section.

\subsection{Step one: determining causes and impacts of degradation of ecosystems, climate, and social-systems}

Step one of the process to determine EbA project options consisted of an initial analysis of:

1. The state of Port Vila ecosystems;

2. Future climate change scenarios; and

3. Ecosystem and socio-economic resilience analysis and mapping (ESRAM) related to the uses of ecosystem services and wellbeing issues and vulnerabilities in Port Vila.

\subsubsection{The state of Port Vila ecosystems: methods and results}

The research team took a 'ridge to reef' approach when devising the EbA projects for Port Vila, acknowledging that the terrestrial, freshwater, and coastal (including reef) ecosystems of small islands are highly interconnected (Delevaux et al., 2018). This meant the project boundaries were determined by the wider water catchment area that Port Vila 


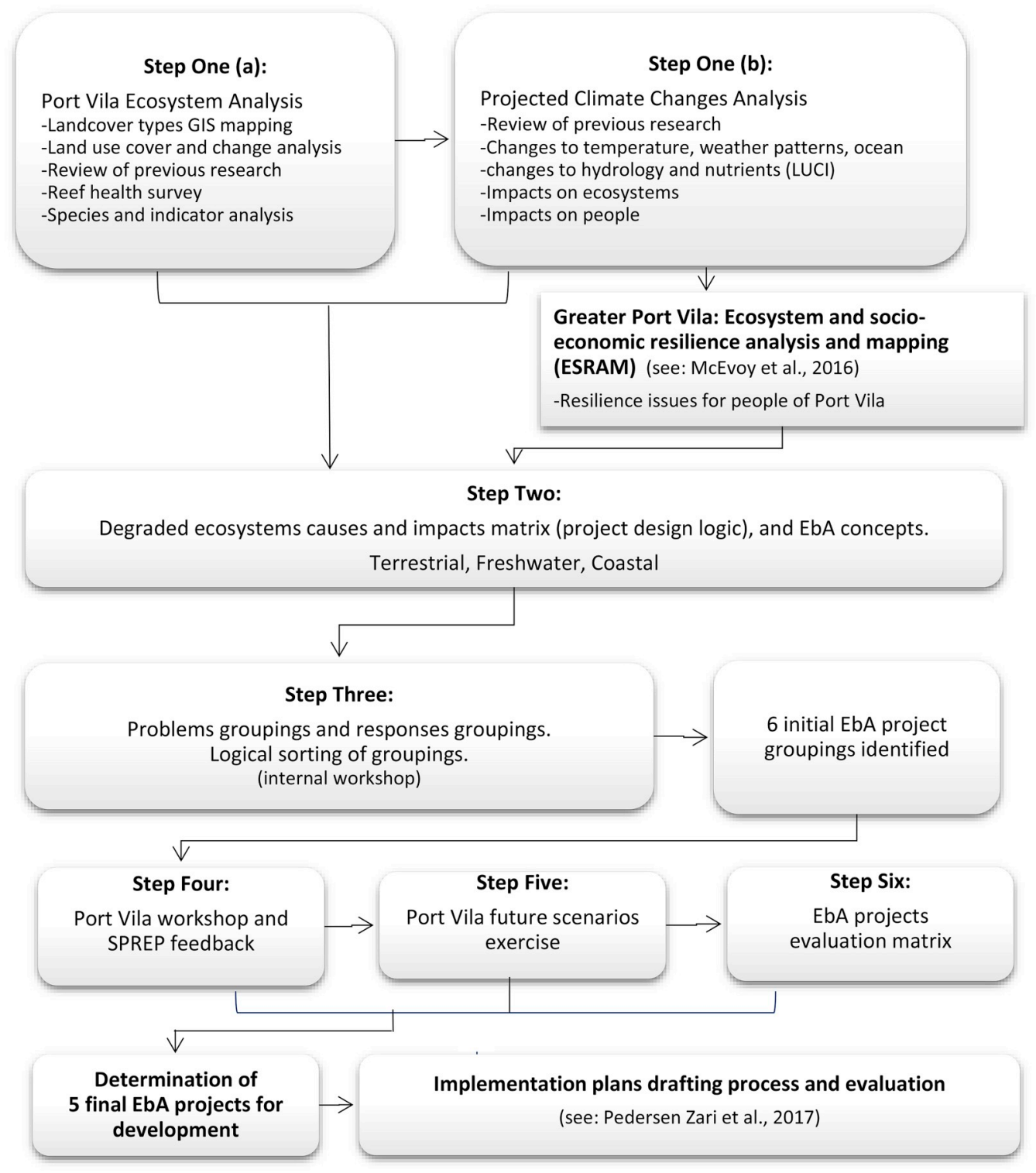

Fig. 2. EbA project development process (adapted from Blaschke et al., 2017).

is situated in, rather than the Port Vila municipality boundaries related to the built-up areas. The state of Port Vila's ecosystems was assessed through: creating a land cover map in the GIS environment derived from satellite imagery and ground truthed data; measuring the extent of land cover types and the current state of ecosystems; analysing and mapping land cover change and the extent of urban sprawl using ArcGIS; conducting direct observations through brief field surveys; undertaking expert interviews; compiling key native flora and fauna data; and through an analysis of flows of water, sediments and nutrients using a digital land management decision support tool called Land Utilisation and Capability Indicator (LUCI).

Ecosystem degradation and land cover transformation resulting from human activities have had widespread impacts on the 'intactness' of the natural ecosystems over time in Vanuatu (SPREP, 2013; DEPC, 2014). Thus, a spatial assessment of Port Vila's ecosystems, including degradation factors, was necessary to provide an ecological picture of the study area. Ecosystem mapping was conducted at two spatial scales using Geographic Information System techniques in the ArcGIS v.10.2.2 and v.10.4.1 environments. 2016 "RapidEye" satellite imagery with a $5 \mathrm{~m}$ resolution was utilised. In order to increase the accuracy of ecosystem mapping, observable objects and colours on the satellite imagery were checked iteratively during the process using available sources of spatial information including Google Maps and Google Earth. In addition, information about the current status of land cover types was gathered from a limited number of local experts who had already undertaken field research in the study area, and a reconnaissance field inspection was undertaken in the lower parts of the Port Vila catchments over a four-day period to provide a more realistic picture, particularly when land cover was not identifiable by remote sensing techniques. In the absence of existing data, the precautionary principle was used to avoid unrealistic approaches for increasing the number of land cover classes/subclasses. The principal aim was to define a relatively accurate and robust land and coastal cover classification system based upon the limited available data (Fig. 3). Detailed information about the methodology employed in this part of the research including mapping limitations is available in Blaschke et al. (2017).

The land cover types developed were broadly consistent with units called "vegetation types" in the Vanuatu Vegetation Map 2012 (Schwetter, 2012) and "ecosystem types" in the ESRAM mapping at multiple scales in Vanuatu (Mackey et al., 2017). Land cover units were developed for coastal marine as well as terrestrial zones in the wider Port Vila catchment area. More detailed land cover types for urban 


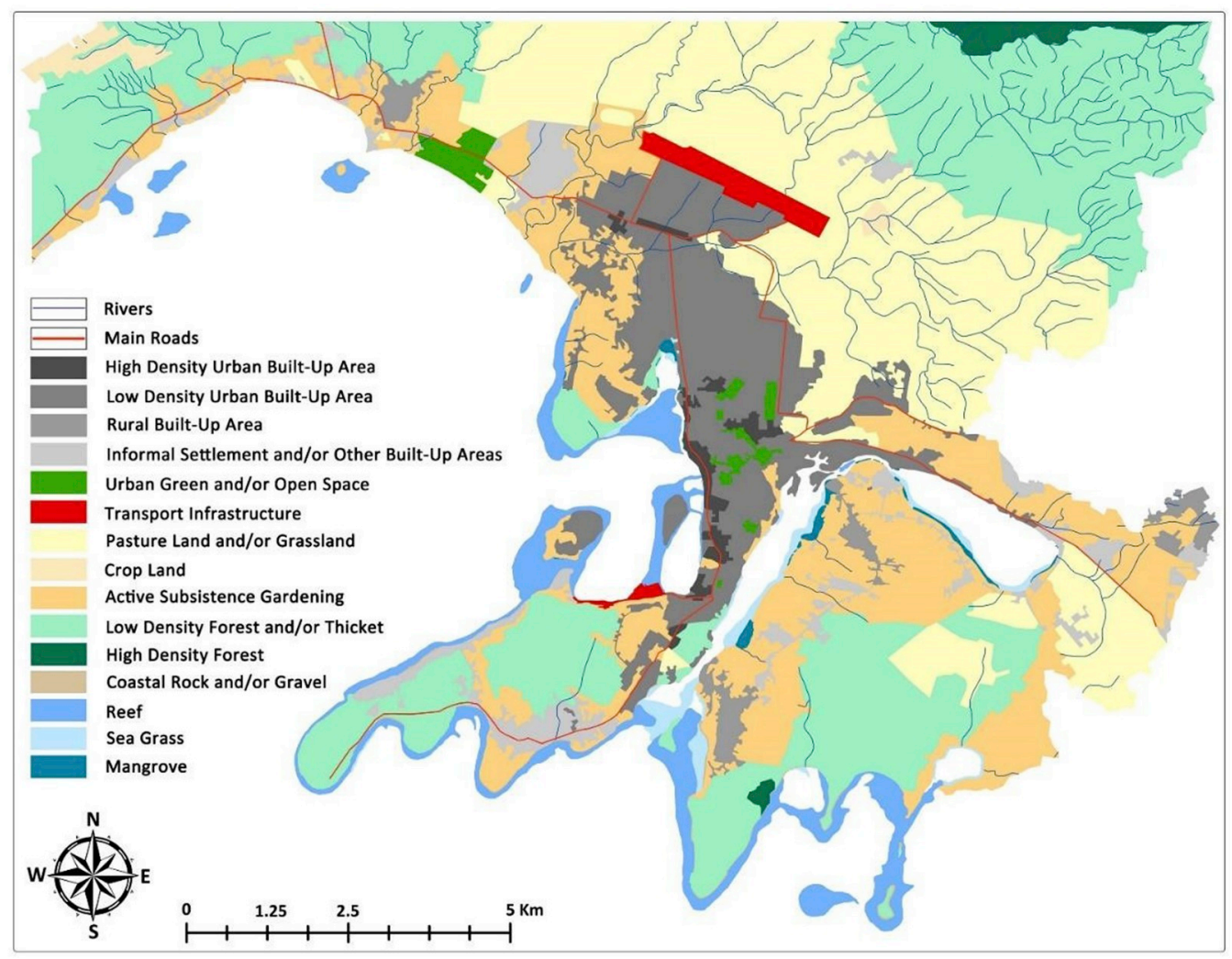

Fig. 3. Metropolitan Port Vila land and coastal cover map at urban scale (source: Blaschke et al., 2017).

built-up areas were developed, primarily for mapping at a more detailed scale for the Greater Port Vila area.

The land cover units were then remapped using transformation categories (Blaschke et al., 2017) to produce a map of ecosystem condition and land transformation (Fig. 4). Fig. 4 shows that the degree of transformation generally increases towards the core of the Port Vila $\mathrm{CBD}$, and that the forest in upper catchments is the largest area of intact ecosystems. However, there are some small areas of less modification

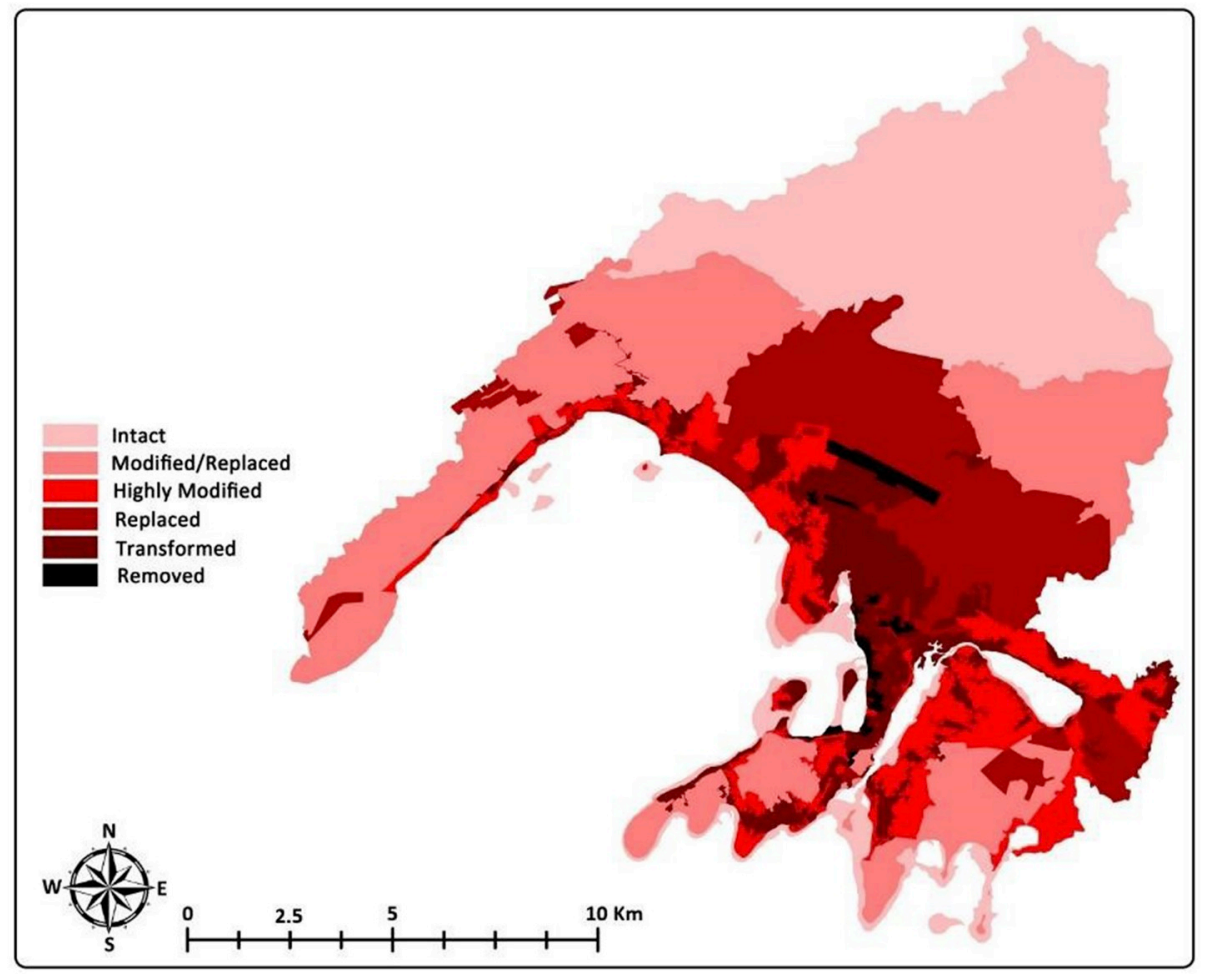

Fig. 4. Map of ecosystem conditions and land transformation in Port Vila catchments (source: Blaschke et al., 2017. 
and transformation relatively close to the Port Vila centre.

Analysis of results showed that a little over one-third of the Port Vila catchments is still substantially intact forest. As the island was almost entirely forested before human settlement, this suggests that about two thirds of the catchment area has been modified or transformed by human disturbance including widespread agricultural practices, deforestation and urban sprawl. Although the general directional trend is towards degradation and loss of intactness in Port Vila ecosystems, the ecological changes are dynamic, with changes in both directions between different land cover types and degrees of modification. Changes towards more intact vegetation may involve significantly different and potentially invasive species combinations than in the original vegetation. Population density-related deforestation due to shifting agriculture raises concerns for metropolitan Port Vila given the known and likely future population increase there.

Terrestrial mapping was supplemented by reef health surveys. These were critical given the continued high dependence of many Port Vila residents on reef ecosystems (McEvoy et al., 2017). A rapid assessment of the benthic community of selected reefs around Port Vila was carried out using point intercept techniques. Four sites were selected according to significance to local communities and the tourism industry, accessibility, and proximity to terrestrial pollutants. At each site, transects (4 $20 \mathrm{~m}$ or $320 \mathrm{~m}$ replicates separated by $5 \mathrm{~m}$ ) were laid randomly along reef contours at a depth of $\sim 10 \mathrm{~m}$. The substrate was photographed and the benthic type was recorded every $50 \mathrm{~cm}$ consistently with Reef Check categories (Hill and Wilkinson, 2004). A series of interviews were conducted with expert local divers to further determine spatial and temporal trends in reef condition. These divers had extensive knowledge of coral and fish species in Port Vila, and an adequate to good understanding of reef ecosystem processes. Percent hard coral cover was used as an indicator for reef health, and results indicated conditions ranging from 'poor' (less than 25\%) to 'good' (50-75\%). These results were mapped to give a spatial indication of where the healthiest and most damaged reefs were located. This revealed that the spatial patterns of reef ecosystem condition are not necessarily determined by proximity to densely populated areas, but that they are affected by both natural and human-induced activities. The reefs around the Port Vila Harbour and a major river, R. Tagabe, are degraded and have very low live coral cover of $15-18 \%$. Seagrass beds in these areas have been lost, mainly as a result of increased sediment input after recent cyclones. The remaining reefs around greater Port Vila have moderate to good live coral coverage (30-65\%). The current key threats to the reef habitat were determined to be: land-based pollution, the aquarium and shell trade, periodic Crown of Thorns Starfish outbreaks, overfishing and natural phenomena e.g. earthquakes, cyclones, tsunamis, and elevated sea surface temperatures during $\mathrm{El}$ Niño conditions. Climate change impacts also interact with, and exacerbate at least some of these threats.

To further determine the current state of Port Vila ecosystems, information on key native flora and fauna was compiled and summarised. This included threat status and reasons for threat, distribution, and potential keystone or critical indicator species to ecosystem function (terrestrial, freshwater, and reef). Published Vanuatu species surveys including the IUCN Red List of Threatened Species (IUCN, 2018), the Critical Ecosystems Partnership Fund (CEPF) Vanuatu Priority Species List (Aalbersberg et al., 2012); the SPREP Vanuatu State of Conservation Country Report for Vanuatu (SPREP, 2013) and Country report to the Conference of Parties to the Convention on Biological Diversity (DEPC, 2014) were drawn upon, along with knowledge of the project research team and personal communication with local experts.

Finally, an analysis was made of flows of water, sediments and nutrients in Port Vila ecosystems, using available data and the Land Utilisation and Capability Indicator (LUCI) - a land management decision support tool and ecosystem process modelling framework). LUCI explores the impact of land management decisions on ecosystem services by modelling a range of ecosystem services (Jackson et al., 2013; Sharp et al., 2017). LUCI was used to evaluate flows, erosion risk and nutrient loads and concentrations under current land cover in the Port Vila catchments and identify areas where changes to land management might improve ecosystem service provision. Soils information was digitised from the Carte Pedologique de Reconnaissance of Efate (Quantin, 1971) and the SRTM30 global digital elevation model (DEM) was used. Soils were translated into the top level (soil order) of New Zealand soil classification (Hewitt, 2010 and NZ Soils Portal), based on the descriptions of the Efate soils found in Quantin (1975). Using these inputs, a hydrologically consistent DEM (and other relevant hydrological information) and baseline (current) land cover/soils scenarios were generated. The flood mitigation tool outputs use information on flow direction and accumulation (amongst other information) to produce maps of flood mitigation and risk. In terms of water quality, terrestrial load and in-stream nitrogen and phosphorus nutrient concentrations were determined using a modified export coefficient approach (Trodahl et al., 2017). Erosion and sediment delivery was modelled using the Compound Topographic Index (CTI) (Thorne and Zevenbergen, 1990), with associated outputs identifying areas vulnerable to erosion and then those areas which are vulnerable to erosion and have an unmitigated flow connection to a water way.

Results indicate that lowland areas of the catchments are at the most risk from accumulating water flows, sediment delivery and nutrients. These areas drain directly to important marine areas, meaning delivery of sediment and nutrients in these areas could have an impact of these ecosystems. Insufficient drainage systems and degraded watersheds (especially on river margins) compromise Port Vila's ability to cope with flooding even under current average conditions. Any increase in rainfall or storm surges will exacerbate this issue (Trundle and McEvoy, 2015). In addition, standing water resulting from poor drainage systems has implications for local human health and is likely to have contributed to outbreaks of dengue fever and malaria that have occurred in Efate (Roth et al., 2014). Vector control through good freshwater management near to houses continues to be an integral component of vector-borne infectious disease control (Elder and Lloyd, 2006). Water shortages will also have human health impacts. LUCI identified terrestrial areas which can be targeted to reduce these adverse impacts. Areas of pasture are the main source of nitrogen, while active subsistence gardening contributes the most phosphorus. Areas most vulnerable to erosion are in steeper areas of the catchments around cliff faces and steeper valley walls of the highlands. Further methodological details and results of the ecosystem assessment can be found in Blaschke et al. (2017).

\subsubsection{Future climate change scenarios: methods and results}

This part of the research was undertaken through analysis of existing data and literature, and also drew on the results of team and Port Vila community workshops. Statistics and figures related to climate changes in Vanuatu and the Port Vila area were taken from the Pacific-Australia Climate Change Science and Adaptation Planning Program (PACCSAP) (PACCSAP, 2014) and are also consistent with the findings of the Intergovernmental Panel on Climate Change (IPCC) (IPCC, 2013). A series of future climate scenarios based on those considered in the 5th Assessment Report (AR5) were devised to give a range of possible futures likely in Vanuatu. A series of graphs were produced including: historical and simulated surface air temperature time series; historical and simulated annual average rainfall time series; observed and predicted sea level rise; and observed and projected changes in aragonite saturation.

Results showed that temperatures in the Port Vila area have risen $1 \mathrm{C}$ in the past 40 years (Blaschke et al., 2017). Future temperature rise in the Port Vila region is anticipated to be somewhat slower than the global average rate, but all future scenarios show temperatures rising significantly above what has been observed in recent decades. Even with moderate warming scenarios, the occurrence of extreme events increases rapidly (Frame et al., 2017). On average, there is likely to be only a small change in precipitation over the rest of the 21 st century, but variability is expected to increase as a consequence of a moister 
atmosphere combined with circulation changes. The South Pacific Convergence Zone (SPCZ) is predicted to become more variable in its movements in the future (Cai et al., 2012) and the El Niño-Southern Oscillation (ENSO) cycle is expected to be associated with more intense precipitation extremes as the planet continues to warm (Power et al., 2013; Cai et al., 2014; Wang et al., 2017). This is likely to be associated with drier conditions in Vanuatu (Lough et al., 2014). Potential precipitation changes (heavier rainfall or increased incidence of drought) will impact local agricultural systems as well as the health of the native forest. The impacts of more frequent extreme events, such as cyclones, could have cascading impacts on the human population as both local crop production and ability to import goods is likely to be compromised (due to damaged ports and shipping lanes). Sea levels in the western Tropical Pacific have risen at around 4-5 mm/year over the past 20 years, which is faster than the global mean rate of $3.3 \mathrm{~mm} /$ year. This trend is likely to continue. Impacts of sea-level rise on human and natural systems in Vanuatu are exacerbated by Vanuatu's geographic location on a tectonically active subsiding area (Kouwenhoven, 2013). Thus, coastal and marine processes that are affected by sea level rise, such as coastal erosion, are more severe on Vanuatu than on other more stable landmasses in the region. Observed and projected aragonite saturation levels (related to ocean acidification) indicate that reef health may become marginal by 2030 . Furthermore, ocean warming increases the risk of coral bleaching events and Crown of Thorns outbreaks (Uthicke et al., 2015), which could have significant impacts on both Vanuatu's tourism economy and the provision of traditional food. Further methodological details and results of the climate change scenarios can be found in Blaschke et al. (2017).

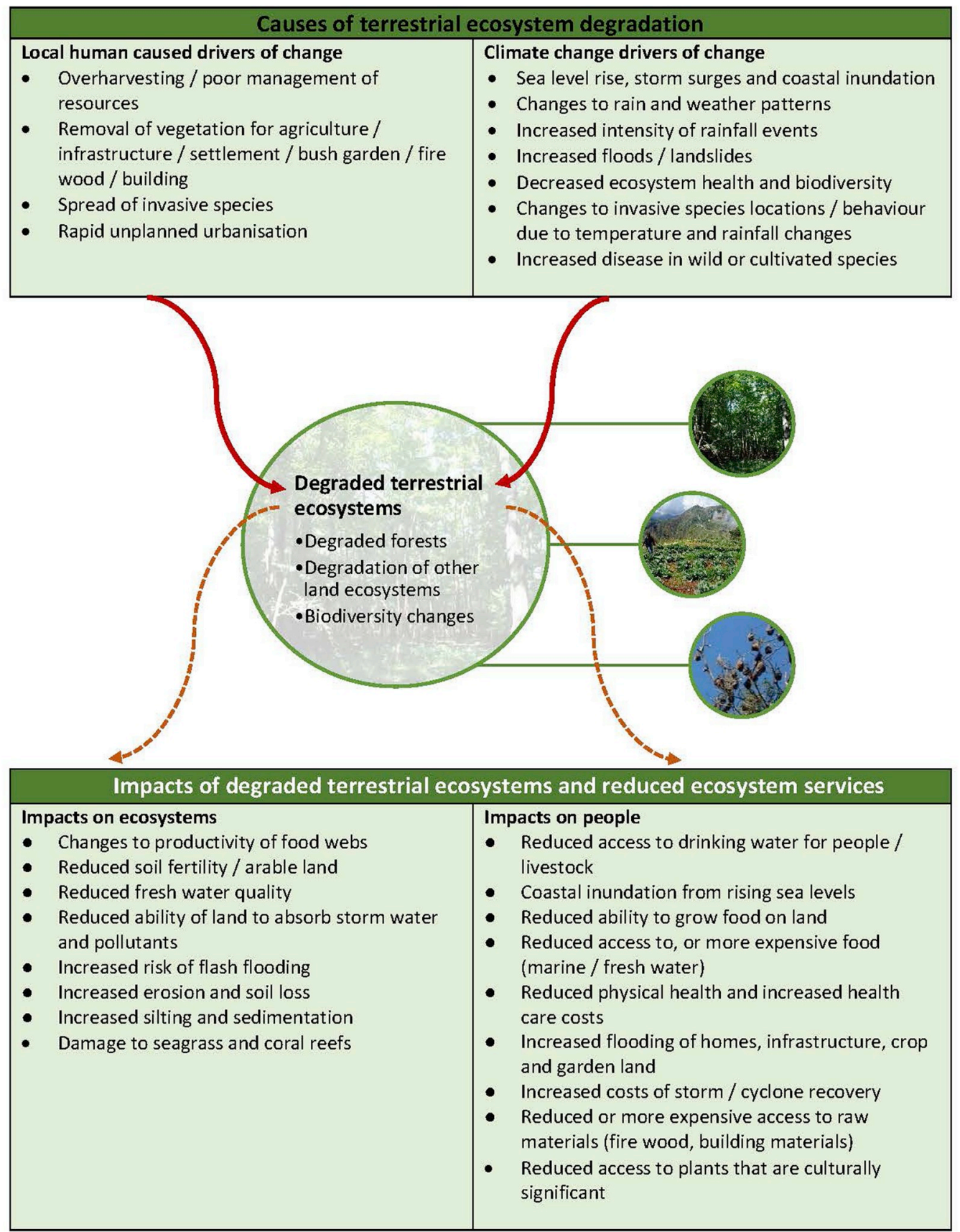

Fig. 5. Degraded terrestrial ecosystems causes and impacts matrix (source: Blaschke et al., 2017). 


\subsubsection{Ecosystem and socio-economic resilience analysis and mapping (ESRAM): method and results}

An earlier PEBACC ecosystem and socio-economic resilience analysis and mapping (ESRAM) report investigated the uses of ecosystem services and wellbeing issues and vulnerabilities in Port Vila (McEvoy et al., 2017). This was based on a series of household surveys and in-depth workshops with residents of ten Port Vila communities located along "ridge to reef" landscape contexts. The findings from this comprehensive participatory social approach to ecosystem services mapping and assessment informed and complimented the approach taken to assessing ecological health (see section 2.1.1). McEvoy et al. (2017) discuss methodologies used and detail findings of their research in depth. Of most relevance to the EbA project planning process was a summary of contemporary pressures on Port Vila ecosystems and people, and a comprehensive preliminary list of adaptation options and potential pilot projects that might address the social and ecosystem service demands and pressures identified.

\subsubsection{Relating the data to impacts on human wellbeing}

The three inputs described above were used to form a set of working matrices to relate ecosystem pressures and local human drivers of change, and their interactions with climate change (and natural disasters), and therefore their impacts on human wellbeing and on other ecosystems. Fig. 5 is an example of a summary of results of this process for terrestrial ecosystems. The process was repeated for freshwater and coastal ecosystems. This working matrix approach, informed by an integration of existing socio-economic resource-use data, ecosystem information, and land-use and climate projections, enabled the creation of sets of causes of ecosystem degradation (by both local human activities and by climate change) along the ridge to reef model. These were related to the resulting impacts (on both ecosystems and people) of this ecosystem degradation. This was also spatialised on three-dimensional ridge to reef transects of the Port Vila catchment to understand specifically where various causes of changes and impacts of change overlap and interact.

\subsection{Step two of the EbA project selection process: EbA project concepts}

Step two involved taking the information from step one to determine a number of logical EbA project concepts that could concurrently address both the causes (human caused and climate change induced) and impacts (social, economic and ecological) of ecosystem degradation. The following information was assembled for each potential EbA project:

strategies and methods for implementation;

- additional ecosystems that would benefit;

- ecosystem services that would be targeted by each project idea;

- spatial and temporal distribution information;

- additional benefits; barriers to implementation;

- opportunities and complementarities to other non SPREP projects;

- potential precedents and case studies; and

- additional resources and references.

This information was added to the working matrices and became part of the project logic design for the creation of initial lists of potential EbA responses to identified issues and vulnerabilities. These lists were cross referenced with the suggested projects to increase community wellbeing and resilience in Port Vila, as suggested by McEvoy et al. (2017).

In order to make the EbA concept easier to grasp for the community, and more applicable to the Port Vila context, the EbA projects options process initially focused on highly tangible elements of increasing resilience. Namely, increased food security, water security, and energy security, and access to healthy, safe, and culturally and climatically appropriate shelter. This 'baskets of resilience' approach enabled initial conceptualisation of the proposed project groupings for community

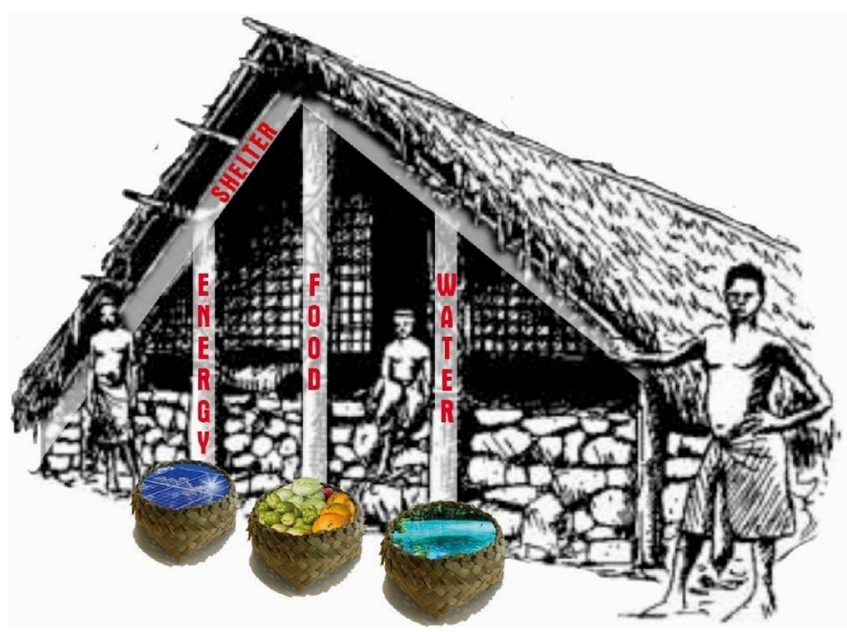

Fig. 6. 'Baskets of resilience' and cultural model for approaching EbA project design (source: Blaschke et al., 2017).

participatory consultation in a way that was intended to be culturally relevant and accessible. Fig. 6 illustrates how these elements of resilience can be conceived and how additional metaphors can be read into projects as appropriate when communicating EbA projects to residents. For example, the strong stone base could relate to knowledge and celebration of culture, and the people in the image could represent healthy family or community relationships. Both of these are also important elements of resilient communities and relate to the cultural context of Port Vila.

A strict EbA approach focuses only on protecting or regenerating natural ecosystems themselves. However, Port Vila is a developing city, where human wellbeing is affected by urban development issues. Because these in turn are major drivers of ecosystem degradation (as ascertained in step one), some of the EbA projects proposed were 'hybrid' EbA projects. This means they are a mixture of 'soft' direct interventions into ecosystems (protecting or regenerating naturally occurring ecosystems), and 'hard', engineered or built infrastructure approaches to increasing ecosystem health indirectly, and therefore also human wellbeing. This is appropriate given that the focus was on an already highly modified landscape that is rapidly urbanising, meaning a large amount of building and infrastructure development is already occurring (Chung and Hill, 2002; Westoby and Brown, 2007). The intention was that $\mathrm{EbA}$ projects could be a vehicle for directing some of the rapid and at times unplanned development of the area so it is more ecologically, climatically, and socially effective.

\subsection{Step three of the EbA project selection process: sorting and groupings}

The long list of potential EbA projects for the Port Vila region generated in step two (for details see appendix 4.2 in Blaschke et al., 2017) required careful organisation and editing to sort these into manageable and understandable groupings. This was step three of the EbA project selection process. The six project groupings are:

1. Integrated Catchment Project for Water Security: an integrated catchment project from ridge to reef, including protected forest area in water catchment.

2. Urban \& Peri-urban Agriculture: diversified and resilient urban/periurban agriculture and fuel production.

3. Urban forests/Agroforestry: strategic introduction of multi-value trees and vegetation to urban areas and coastal environments.

4. Coastal Ecosystems Regeneration: reducing human caused stressors to coral reefs, and regenerating key coastal mangrove and seagrass ecosystems. 
5. Integrated urban water systems - fresh/grey/black: reducing stressors to riparian systems and ground water with a focus on harvesting drinking water, coastal and reef systems health.

6. Sustainable urban development and housing: providing a model of sustainable housing/urban development to address rapid urban growth and climate change.

\subsection{Step four of the EbA project selection process: Port Vila workshops}

In June 2017, several members of the research team and SPREP representatives convened a community and stakeholder workshop in Port Vila and presented the six initial project groups determined in step three. This process to engage the community and garner stakeholder feedback became step four of the EbA project design and selection process. Approximately 40 people from a range of different communities, non-governmental organisations, and government departments attended. Because data on Port Vila and Vanuatu is general is lacking, it was vital to communicate with locals about the accuracy of the research. EbA is essentially about relationships between people and ecosystems, and therefore it was also of great importance that the process of developing the EbA projects was as participatory with the community as time allowed for. The first workshop session aimed to facilitate community discussion and confirm the main causes of ecological degradation that had previously been identified by the team, and to map the impacts or vulnerabilities arising from these. Issues identified by the community were placed on an illustrated transect (a three-dimensional slice of the island) of the Port Vila catchment area (Fig. 7). Earlier work with NiVanuatu (Vanuatu citizens and residents of other ethnicities) using three dimensional physical models to initiate discussions had proven to be more successful than using traditional maps. This was the basis of the decision to use a three-dimensional representation of the areas in an effort to make it easier for local people to interact with the data.

The second breakout session was designed to gauge reaction to the presentation of the initial six proposed EbA project groupings (devised in step 3). Workshop participants were asked to discuss the merits or difficulties of these potential projects and if possible, to locate some of these issues on the transect. The feedback received during this process informed the prioritisation of the final EbA projects that were then developed into detailed implementation plans.

\subsection{Step five of the EbA project selection process: future development scenarios}

In order to evaluate and prioritise the initial EbA project ideas for Port Vila, a development scenarios exercise was conducted to try to predict how each project might work in different possible futures up to 2030. This is a way to evaluate potential risks or future issues that might affect the success of the proposed projects. This informed reorganisation and selection of the final 5 selected EbA projects along with findings from step 4. The most important variables used to devise possible future scenarios were rate of population growth, rate and nature of economic development, and nature and magnitude of climate change impacts. All devised possible future scenarios involve climate change impacts at the high end of the range. The reason for holding climate change impacts constant across all three scenarios was to better indicate the different effects of the drivers that are able to be influenced by people of Vanuatu itself, namely rate of population growth, and nature and rate of economic development. Ni-Vanuatu have little ability to influence global greenhouse gas emissions and therefore global climate change. Furthermore, climate change impacts will not stop in 2030. If actual climate change impacts turn out to be lower than the high end of the ranges predicted, this does not mean that Port Vila will avoid the impacts at the higher end of the ranges; it simply means that Port Vila will experience the impacts at the high end of the range some time later than 2030. Details of the scenarios are found in Blaschke et al., (2017). The scenarios planning exercise indicated that there will still be significant resilience challenges for Port Vila, regardless of the adaptation and development paths taken, because of high climate change impacts that are beyond the control of Ni-Vanuatu. This suggests that it would be instructive to consider future scenarios over a longer timeframe, and/or conduct scenario planning at regular long-term intervals.

\subsection{Step six of the EbA project selection process: prioritisation and comparison of $E b A$ projects}

After the community workshop, feedback from SPREP in Port Vila, and a series of internal workshops and meetings, 11 possible targeted projects of high priority, that came from the 6 project groupings conceived in step 3 were identified for further consideration. In order to prioritise these further, the next stage involved identifying the outputs and main components of each of these projects and then comparatively assessing each project in terms of:

- relative importance relating to adaptation to climate change and overall resilience;

- relative magnitude of the effect that the project's outputs on improving adaptation to climate change and overall resilience;

- relative cost of the project;

- relative area, scope and size;

- relative risk of failure to achieve the project's stated outputs;

- relative timeframe for implementation;

- relevance to the 'ridge to reef' frame;

- relative public visibility of the project; and

- extent to which the project complements other existing EbA and nonEbA projects in Vanuatu.

An initial assessment of the 11 projects was done with a comparative matrix using the above assessment criteria. Results from this exercise enabled the initial 11 possible EbA projects to be narrowed to 5 high priority ones. In the project selection a simple form of cost-benefit was used. The relative benefits of the different projects were made commensurate by assessing them in terms of 'relevance to major climate change adaptation or resilience issues' and 'magnitude of the contribution that the project would make to responding to these issues'. The

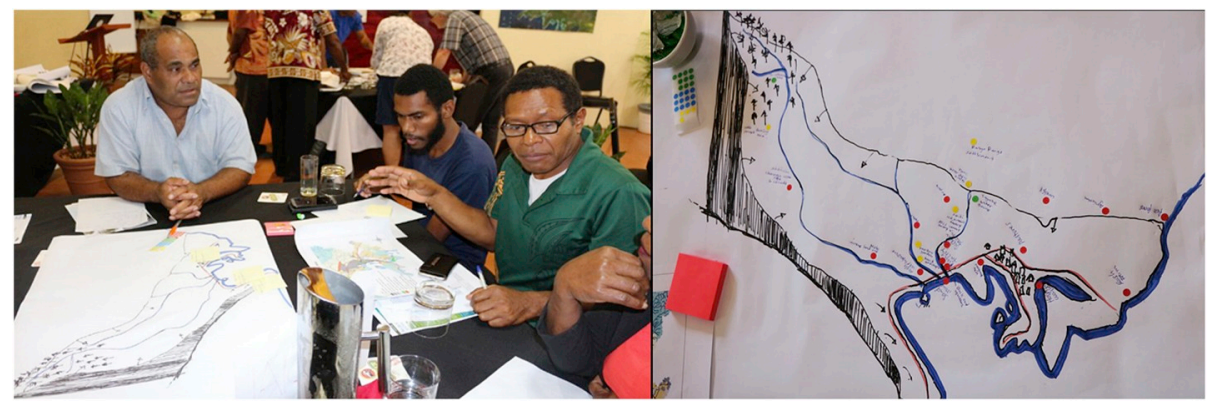

Fig. 7. Participatory transect mapping of the project groupings. PEBACC workshop June 2017. 
relative costs were estimated in terms of Low $(<\$ 0.5 \mathrm{M})$, Medium ( $\$ 0.5 \mathrm{M}<\$ 1 \mathrm{M})$, or High $(>\$ 1 \mathrm{M})$. This was a broad preliminary estimate before any specific costings were sought.

Results from the matrix analysis were then illustrated as radar graphs (Fig. 8). The relative position and angle of the axes is not informative, but the different areas of each shape created enabled quick visual comparison of the different projects across the key prioritisation criteria. In this case a low $(\mathrm{L})$ ranking equates to 1 and a high ranking $(\mathrm{H})$ equates to 5 across the criteria. This means the larger the shape that is created for each project on the radar graphs, the better it ranks across all of the criteria.

What Fig. 8 shows, is that the final five EbA projects proposed were a mixture of high risk and low risk, and higher and lower cost ones. All tend to rate highly in terms of relevance to resilience and adaptation to climate change, estimated magnitude of benefits generated, and complementarity to other Vanuatu development or ecological regeneration projects as well as the other proposed EbA projects. The five key EbA projects selected for development in the Port Vila context as summarised below.

\subsubsection{EbA project 1: Tagabe Riparian corridor regeneration project}

The Tagabe Riparian Corridor Regeneration Project is an integrated catchment management programme of activities focused on the riparian margins of mid to lower catchment streams in the Tagabe catchment. The aim of this project is to develop a resilient water catchment system that supports human wellbeing and the local economy through the protection and enhancement of ecological infrastructure capable of maximising the delivery of ecosystem services for the Port Vila population. This will be achieved through: the protection and enhancement of woody vegetation along stream banks and on adjacent lands; sustainable land management practices on adjacent lands delivering reduced sedimentation and reduced non-point source pollutants; and reduction/elimination of point source pollutant delivery to streams.

\subsubsection{EbA project 2: restoration and protection of coastal vegetation project}

This project aims to restore and protect coastal vegetation, particularly mangrove habitats, along key parts of the greater Port Vila coastline. The project builds on and implements earlier work under the Mangrove Ecosystems for Climate Change Adaptation and Livelihoods (MESCAL) programme (Baereleo et al., 2013). This will be achieved through: addressing specific threats to mangrove and other coastal habitats; implementing robust measures for the full offsetting of mangrove and other coastal habitats if unavoidable loss occurs; and implementation and monitoring of site-specific replanting and restoration projects in key Port Vila sites.

\subsubsection{EbA project 3: intensification of Suburban and peri-urban home gardens project}

Maintaining, or improving, food and cooking fuel security for communities in Greater Port Vila over the period to 2030 and beyond would make a major contribution to improving resilience and overall health and well-being. This could be done if the extent and productivity of home gardens (which are common throughout Port Vila) were to be increased and if home gardens were made as resilient as possible to the impacts of climate change. Specific aims and outcomes of the project are to provide cost-effective support to households in the urban and periurban areas of Port Vila through: intensified food production, firewood supply, medicinal plants, construction materials and mat- and basket-making materials production in home gardens; effective use, preservation and storage of produce from home gardens and of firewood; dietary nutrition education; increase understanding of preservation of the culturally significant natangura and pandanus plants; and the inclusion of efforts to increase urban and peri-urban agriculture and freshwater aquaculture in the Greater Port Vila Planning Scheme.

\subsubsection{EbA project 4: urban trees project}

This project involves the strategic introduction of multi-value trees
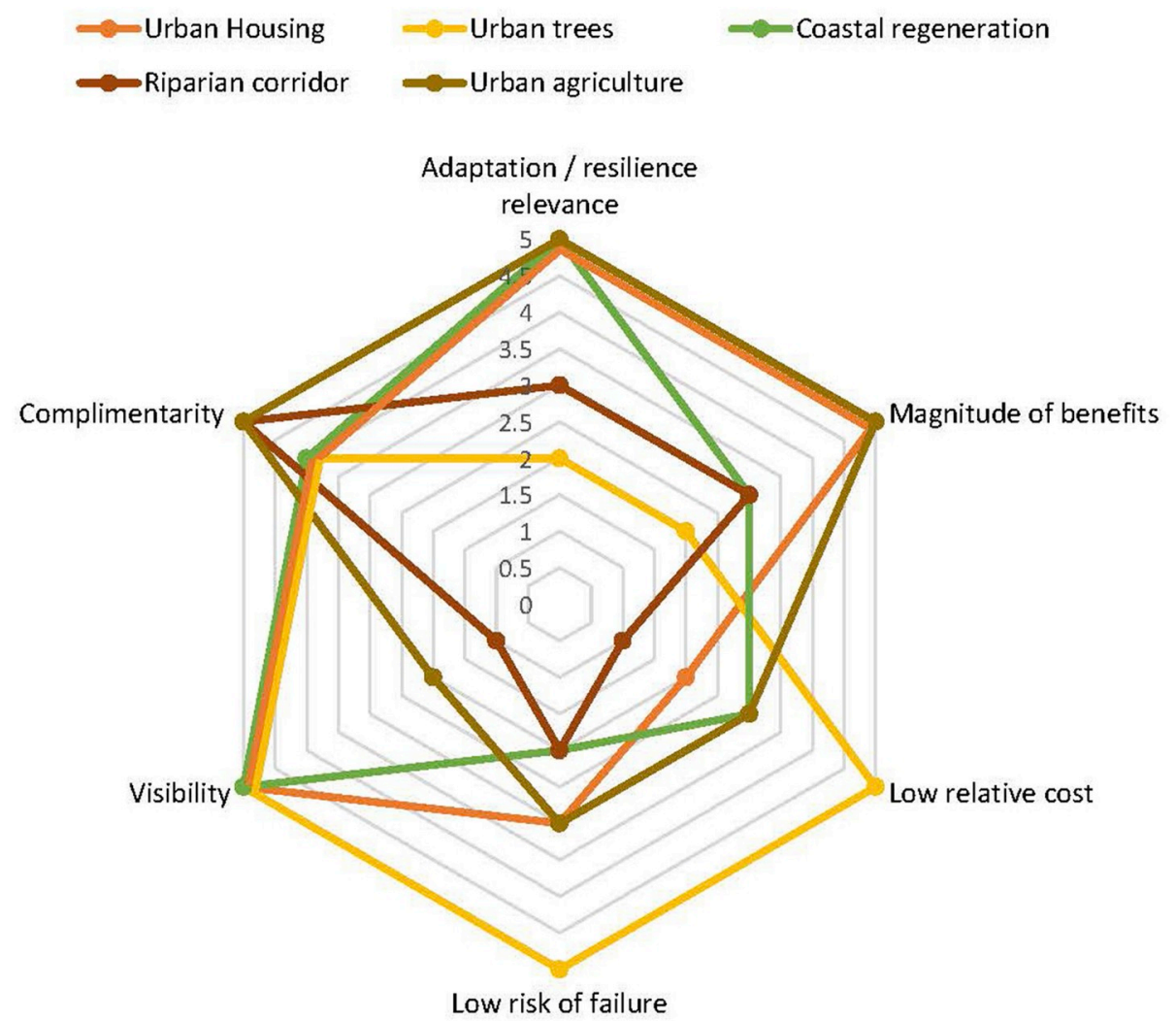

Fig. 8. Radar Comparison of different ranking criteria for final five proposed EbA projects (source: Blaschke et al., 2017). 
and vegetation to key urban areas and coastal environments in Port Vila. This project is a low-risk and low-cost project that could be implemented rapidly, would be highly visible to the public and may thereby act as a catalyst for public interest in, and valuing of, other PEBACC projects. This project focuses on increased food security and access to raw materials, and the use, sharing, support and preservation of traditional knowledge and possible benefits to tourism within the city. This will be achieved by: determination of key sites for intervention in the built-up area of Port Vila; development of planting schemes for existing major vehicle and foot transport pathways in the built-up areas of Port Villa; establishment of nurseries and seed sources to support regeneration on Efate; and the creation of a living urban library of the useful plants of Efate to educate, provide tangible resources, increase vital urban ecosystem services, and to act as a seedbank. Benefits include: mitigation of some of the effects of climate change by creating cooler urban microclimates and shade during hotter weather; improved air and water quality; reduction of storm water runoff; protection of waterways and coastal ecologies; and preservation of traditional knowledge.

\subsubsection{EbA project 5: sustainable housing development project}

This project involves the design and implementation of a demonstration housing project in Port Vila. The goal is to introduce concepts related to social, economic and environmental sustainability into new housing developments and the retrofit of existing informal settlements. Specific aims and outcomes include the integration of the following features into new urban developments: community participatory design (design development); food production (urban agriculture); energy production (agroforestry; renewable energies); integrated water systems (stormwater, greywater and blackwater management); waste management (food); site sensitive landscape architecture (sociability, drainage, comfort, biodiversity, etc.); bioclimatic architecture (passive solar design, shading, ventilation, insulation, appropriate materials, rain water harvesting, etc.); economic viability; and effective future focused city planning (leveraging local resources, traditional technologies, etc.).

\subsection{Step seven of the EbA project selection process: implementation plans drafted and evaluated}

The final step of the EbA process employed in this research was to prepare implementation plans (published in full in Pedersen Zari et al., 2017). The implementation plans provided the detail and justification for the projects in terms of:

- Project aims and purpose

- Background

Project justification

- Issues and vulnerabilities addressed by the project

- Benefits of the project

- Intervention logic

- Project location (ridge to reef position)

- Timeframe and sequencing

- Description of project components

- Implementers and stakeholders

- Education, research, training, and public awareness opportunities

- Indicative costs and resourcing requirements

- Financing, project design implications and opportunities for scaling

- Monitoring and governance aspects of the project

- Addressing barriers to implementation and project success

- Project opportunities

- Relationships to other projects

The detailed intervention logic for each of the proposed projects addressed the issues of: significant risks to the successful implementation of the project and how these risks can be managed; how the outputs of the project contribute to improved adaptation to climate change and overall resilience; and the expected magnitude of the effect of the project's outputs on improved adaptation to climate change and overall resilience.

\subsection{Next steps after the implementation planning process}

After the implementation plans were delivered to SPREP, a further evaluation and refinement process took place based on maximising impact within current time and budget availability. It was decided that some projects would be progressed and others modified, while some were put on hold dependant on availability of future funding.

The next stage in actualising proposed EbA projects would be a detailed project design stage. The work done in this stage would answer a number of outstanding issues identified in the implementation plans report (Pedersen Zari et al., 2017), including how each project: would be structured; how it would be physically implemented; who would be involved; what resources it would require and when; and project financing and governance considerations. Blaschke et al. (2017) provide developed examples of how the following aspects of project financing could work in an EbA context: performance-based and payment on delivery models for project outcome delivery; pilot activities to pave the way for methodology refinement and then replication and scaling up; self-financing project implementation; incentive-based financing; financing for durability including equitable benefit sharing arrangements; quality assurance measures; co-financing arrangements; carbon credit finance; and payment for environmental management services (PEMS).

Community governance and participation should be an important feature of EbA project architecture, and is a key enabling condition of any resilient community capable of proactively adapting to challenges such as climate change. Part of project development, therefore, needs to include evaluation of community governance capacity, and any need for governance capacity building. Risk management plans should also be incorporated into developed EbA project planning and should include standard operating procedures and associated measures in place (and sometimes budgets) for responding to risk events should they occur.

Monitoring, reporting and verification (MRV) is crucial to EbA projects, and success and future funding often depends on measurable outcomes. Measurement therefore, should be a core feature of project design and implementation. An efficient MRV system is one capable of delivering high scientific rigour at a low cost. This requires defining lowcost-to-measure proxies for the suite of beneficial outcomes delivered. Keystone proxies can then be subjected to the necessary due diligence of MRV without the project budget becoming burdened with measurement over outcomes. Such measured proxies also need to have transparent attribution to project activities and outputs.

Sets of biological indicators of ecosystem condition indicators of an integrated $\mathrm{EbA}$ programme are needed to track progress on environmental states as well as broader development outcomes, such as those based on a conventional pressure-state-response framework (Smeets and Weterings, 1999). Because of this, a set of biological indicators for ecosystem health specific to Port Vila were developed for use in monitoring of future EbA projects (Blaschke et al., 2017). Good environmental and resilience indicators are SMART (specific, measurable, attributable, realistic, and time-bound) (Schomaker, 1997; Niemeijer and de Groot, 2008). Not all the indicators developed have all the SMART attributes due to the current monitoring capacity in Vanuatu, but they are useful for robust monitoring and may be capable of being developed for use in 'citizen science' approaches to ecosystem monitoring and conservation.

\subsection{Findings and discussion: implications of using the EbA methodology}

The work carried out in this study confirms the earlier assertion that biocultural diversity concepts and the needs of local people must be understood and be at the forefront of project planning. Participatory design, rather than just consultation is important to the process. Because 
of the complex nature of urban EbA project design, it is crucial that the research team be multidisciplinary. The skills of ecologists and marine biologists, climatology and climate change experts, socio-ecological and ecosystem services experts, economists, and experts in urban design and landscape architecture are needed. This means that EbA project development can take considerable time and that frequent facilitated group dialogue is needed. Five additional key findings and recommendations regarding the EbA process have been deduced from the Port Vila PEBACC project:

1. Ecological, climatic, and socio-cultural data that is metric, spatial, and both quantitative and qualitative where appropriate is vital as a basis for EbA project development. In a developing nation context this can be difficult to find, so considerable time and effort must be allocated to gathering or generating this as part of the EbA process. This also illustrates the importance of continual engagement with local communities.

2. The timeframe and cost (and outcomes) of implementing projects depends critically on the detail of how the projects will be implemented. This too requires ongoing, time-consuming engagement with local communities and other stakeholders, and a readiness to adapt to on-the-ground realities as projects are implemented.

3. Urban EbA projects benefit greatly from being conceived holistically as parts of socio-ecological systems that extend beyond just the urban area itself. Including the wider water catchments supporting the Port Vila urban area of the city was crucial.

4. EbA projects are complex and require the ability to understand and assess potential benefits, costs and risks across multiple factors including carefully considered future scenarios. The use of tools such as matrices and radar diagrams were useful to enable holistic development of the EbA projects to occur, as well to communicate potential benefits of proposed projects.

5. A feature of urban areas within developing nations, at least in Vanuatu and likely other Pacific Island nations, is a complex overlapping landscape of past and current governmental and international aid financed projects, that focus on various development, environmental, and wellbeing issues. It is important to understand how these projects relate to each other and to potential new EbA projects in terms of space, time, and aims. This again demonstrates the importance of consistent and frequent stakeholder interactions.

\section{Conclusion}

At the commencement of this project, there was little literature describing proven EbA project design methods, particularly for an urban context. The intention then of publishing the EbA methodology described in this paper is to stimulate debate in the EbA community, to refine and critique existing EbA processes, and ultimately to make it easier to engage in EbA project design in a developing nation context. Although any EbA process will need to be specific to its cultural, ecological, and climatic context, elements of project design will be transferable. The methodology described for devising urban EbA projects has been demonstrated to be applicable in practice, and was developed after considerable discussion, experimentation, trial and error, and refinement.

The approach described may be applicable to other SIDS or developing nation contexts, however the authors recommend thoroughly assessing the method's suitability for other situations and adapting it to suit local cultural and ecological contexts. The unique circumstances that supported this process in Vanuatu included the fact that population and land areas are relatively small, making potential for change easier possibly. Vanuatu is known to be a highly vulnerable nation in terms of natural disaster risk and climate change impacts, and the people of Vanuatu have had to cope with large scale disasters in the near past (such as Cyclone Pam in 2015). This means perhaps a more willing attitude towards urban adaptation and/or that a sense of urgency is present. Finally, because Vanuatu is a developing nation that will be affected by climate change, international funding was available for the EbA project described. This fits into a national context of multiple overlapping international aid financed development, health, and education projects, and associated with these projects, people skilled in aid related development work. Future research focused on the methodology described could include how the methodology could be shortened, or modified to suit smaller or poorer coastal settlements with less access to funding. A thorough comparison of outcomes and findings related to different EbA and related methods will also be useful in future research.

To conclude, like many urban centres in developing nations, particularly in small island nations, Port Vila (and Vanuatu as a whole) is changing rapidly due to both the actions of local people and because of global climate change. Urgent action is required to at least maintain, and where possible increase human wellbeing, and to develop resilience to inevitable climate change impacts. Ecosystem-based adaptation projects, which tend to be more cost-effective, more flexible and have multiple additional benefits to them, represent one way to do this. Such initiatives are of great importance to safe-guard the living standards and local customs of peoples in developing nations in both the short and long terms.

\section{Declaration of competing interest}

The authors declare that they have no known competing financial interests or personal relationships that could have appeared to influence the work reported in this paper.

\section{Acknowledgements}

We wish to acknowledge the following people for their helpful assistance at various stages: $\mathrm{H}$. Timmermans, PEBACC project manager; the Port Vila Municipal Council; the Vanuatu Department of Climate Change; the Vanuatu Department of Environment Protection and Conservation; people who attended Port Vila workshops; and M. Namdar and A. Taylor for digitising soils data. The research reported on in this article comes from The Pacific Ecosystem-based Adaptation to Climate Change (PEBACC) Project which was implemented by the Secretariat of the Pacific Regional Environment Programme (SPREP), and funded by the Bundesministerium für Umwelt, Naturschutz und nukleare Sicherheit of the German Federal Government.

\section{References}

Aalbersberg, B., Avosa, M., James, R., Kaluwin, C., Lokani, P., Opu, J., Siwatibau, S., Tuiwawa, M., Waqa-Sakiti, H., Tordoff, A.W., 2012. Ecosystem Profile: East Melanesian Islands Biodiversity Hotspot. Critical Ecosystem Partnership Fund.

Baereleo, et al., 2013. Biodiversity Assessments Technical Report (Eratap and Amal/Crab Bay). Government of Vanuatu, Port Vila.

Bai, X., Dawson, R.J., Ürge-Vorsatz, D., Delgado, G.C., Barau, A.S., Dhakal, S., Roberts, D., 2018. Six research priorities for cities and climate change. Nature 555 (7694), 23-25.

Birkmann, J., Garschagen, M., Mucke, P., Schauder, A., Seibert, T., Welle, T., Rhyner, J., Kohler, S., Loster, T., Reinhard, D., Matuschke, I., 2014. World Risk Report 2014. Bündnis Entwicklung Hilft and United Nations University Institute for Environment and Human Security (UNU-EHS), Berlin.

Blaschke, P.M., Pedersen Zari, M., Archie, K.M., Jackson, B., Komugabe-Dixson, A., Livesey, C., Weaver, S., 2017. Port Vila. Ecosystems, Climate Change and Development Scenarios, Vanuatu. SPREP, Apia, Samoa. https://www.sprep.org/a ttachments/Publications/IOE/pebacc/port-vila-ecosystems-climate-change-develo pment-scenarios.pdf.

Brink, E., Aalders, T., Adam, D., Feller, R., Henselek, Y., Hoffmann, A., Wamsler, C. 2016. Cascades of green: a review of ecosystem-based adaptation in urban areas. Glob. Environ. Chang. 36, 111-123.

Bündnis Entwicklung Hilft, 2017. World Risk Report Analysis and Prospects (Berlin).

Cai, W., et al., 2012. More extreme swings of the South Pacific convergence zone due to greenhouse warming. Nature 488, 365-369.

Cai, W., et al., 2014. Increasing frequency of extreme El Nino events due to greenhouse warming. Nat. Clim. Chang. 4, 111-116.

Chung, M., Hill, D., 2002. Urban Informal Settlements in Vanuatu: Challenge for Equitable Development. Retrieved from Port Vila. https://mjcs.gov.vu/images/re search_database/Vanuatu_Squatter_Settlement_Study_2002.pdf. 
Cincotta, R.P., Wisnewski, J., Engelman, R., 2000. Human population in the biodiversity hotspots. Nature 404 (6781), 990-999.

Cohen-Shacham, E., Walters, G., Janzen, C., Maginnis, S., 2016. Nature-based Solutions to Address Global Societal Challenges. IUCN, Gland, Switzerland, p. 97.

Connell, J., 2015. Vulnerable Islands: climate change, tectonic change, and changing livelihoods in the Western Pacific. Contemp. Pac. 27 (1), 1-36.

Delevaux, J.M.S., Whittier, R., Stamoulis, K.A., Bremer, L.L., Jupiter, S., Friedlander, A. M., Winter, K.B., 2018. A linked land-sea modeling framework to inform ridge-toreef management in high oceanic islands. PLoS One 13 (3), e0193230.

Department of Environmental Protection and Conservation (DEPC), 2014. Fifth Nationa Report to the Conference of the Parties to the Convention on Biological Diversity.

Eckstein, D., Künzel, V., Schafer, L., 2017. Global Climate Risk Index 2018. Germanwatch, Bonn.

Eigenbrod, F., Bell, V.A., Davies, H.N., Heinemeyer, A., Armsworth, P.R., Gaston, K.J., 2011. The impact of projected increases in urbanization on ecosystem services. Proc R. Soc. Biol. Sci. 278 (1722), 3201-3208.

Elder, J., Lloyd, L., 2006. Achieving behaviour change for dengue control: methods, scaling-up and sustainability. Rep. Sci. Work. Group Dengue 140-149.

Frame, D., Joshi, M., Hawkins, E., Harrington, L.J., D Roiste, M., 2017. Population-based emergence of unfamiliar climates. Nat. Clim. Chang. 7 (June), 407-412.

Garschagen, M., Romero-Lankao, P., 2015. Exploring the relationships between urbanization trends and climate change vulnerability. Clim. Change 133 (1), 37-52. https://doi.org/10.1007/s10584-013-0812-6.

Geneletti, D., Zardo, L., 2016. Ecosystem-based adaptation in cities: an analysis of European urban climate adaptation plans. Land Use Policy 50, 38-47. https://doi. org/10.1016/j.landusepol.2015.09.003.

Hallegatte, S., Bangalore, M., Bonzanigo, L., Fay, M., Kane, T., Narloch, U., VogtSchilb, A., 2015. Shock Waves: Managing the Impacts of Climate Change on Poverty. The World Bank.

Hewitt, A.E, 2010. New Zealand soil classification. Landcare Res. Sci. Ser. 1.

Hill, J., Wilkinson, C., 2004. Methods for Ecological Monitoring of Coral Reefs. Australian Institute of Marine Science, Townsville, Australia, p. 117, Version 1.

Hills, T., Carruthers, T.J., B Chape, S., Donohoe, P., 2013. A social and ecological imperative for ecosystem-based adaptation to climate change in the pacific islands. Sustain. Sci. 8 (3), 455-467.

IPCC, 2013. In: Stocker, T.F., Co-authors (Eds.), Summary for Policymakers. Climate Change 2013: the Physical Science Basis. Contribution of Working Group I to the Fifth Assessment Report of the Intergovernmental Panel on Climate Change. Cambridge University Press.

IUCN, 2018. The IUCN Red List of Threatened Species. Retrieved from, Version 2018-1. http://www.iucnredlist.org.

Jackson, B., Pagella, T., Sinclair, F., Orellana, B.M., Henshaw, A., Reynolds, B., et al., 2013. Polyscape: a GIS mapping framework providing efficient and spatially explicit landscape-scale valuation of multiple ecosystem services. Landsc. Urban Plan. 112, $74-88$.

Keesstra, S., Nunes, J., Novara, A., Finger, D., Avelar, D., Kalantari, Z., Cerda, A., 2018 The superior effect of nature based solutions in land management for enhancing ecosystem services. Sci. Total Environ. 610, 997-1009.

Komugabe-Dixson, A., de Ville, N.S.E., Trundle, A., McEvoy, D., 2019. Environmental change, urbanisation, and socio-ecological resilience in the Pacific: Community narratives from Port Vila, Vanuatu. Ecosystem Services 39, 1-13. https://doi.org/ 10.1016/j.ecoser.2019.100973, 100973.

Kouwenhoven, P., 2013. Profile of Risks from Climate Change and Geohazards in Vanuatu: Draft Report. Hamilton, New Zealand. www.nab.vu/sites/all/file s/documents/03/04/201412:45/risk_profile_report_draft_1.pdf. (Accessed July 2017).

Lough, J., Sen Gupta, A., Power, S.B., Grose, M.R., McGree, S., 2014. Observed and projected changes in surface climate of tropical Pacific Islands (Chapter 2). In: Taylor, M., McGregor, A., Dawson, B. (Eds.), Vulnerability of Pacific Island Agriculture and Forestry to Climate Change. Pacific Community, Noumea, 2016.

Mackey, B., Ware, D., Nalau, J., Sahin, O., Fleming, C.M., Smart, J.C., Connolly, R., Hallgren, W., 2017. Ecosystem and socio-economic resilience Analysis and Mapping (ESRAM) and associated work at multiple-scales in Vanuatu: ESRAM report. In: Griffith Climate Change Response Program Report ESRAM-2.

Magee, A.D., Verdon-Kidd, D.C., Kiem, A.S., Royle, S.A., 2016. Tropical cyclone perceptions, impacts and adaptation in the Southwest Pacific: an urban perspective from Fiji, Vanuatu and Tonga. Nat. Hazards Earth Syst. Sci. 16 (5), 1091-1105.

McEvoy, D., de Ville, N., Komugabe-Dixson, A., Trundle, A., 2017. Greater Port Vila Social Mapping and Analysis of Ecosystem Use. SPREP, Apia, Samoa.

McPhearson, T., Karki, M., Herzog, C., Santiago Fink, H., Abbadie, L., Kremer, P., Perini, K., 2018. Urban ecosystems and biodiversity. In: Rosenzweig, C., Solecki, W., Romero-Lankao, P., Mehrotra, S., Dhakal, S., Ibrahim, S.A. (Eds.), Climate Change and Cities: Second Assessment Report of the Urban Climate Change Research Network. Cambridge University Press, New York, pp. 257-318.

Mittermeier, R.A., Myers, N., Thomsen, J.B., Da Fonseca, G.A., Olivieri, S., 1998. Biodiversity hotspots and major tropical wilderness areas: approaches to setting conservation priorities. Conserv. Biol. 12 (3), 516-520.
Montanarella, L., Scholes, R., Brainich, A., 2018. The IPBES Assessment Report on Land Degradation and Restoration (Retrieved from Bonn, Germany).

Munang, R., Thiaw, I., Alverson, K., Mumba, M., Liu, J., Rivington, M., 2013. Climate change and Ecosystem-based Adaptation: a new pragmatic approach to buffering climate change impacts. Curr. Opin. Environ. Sustain. 5 (1), 67-71.

Niemeijer, D., de Groot, R.S., 2008. A conceptual framework for selecting environmental indicator sets. Ecol. Indicat. 8 (1), 14-25, 2008.

Pacific-Australia climate change science and adaptation planning Program (PACCSAP). In: Pacific Climate Change Data Portal - Vanuatu Historical Climate Information, 2014. Online Resource, available at: http://www.bom.gov.au/pacific/vanuatu/. (Accessed August 2017).

Pedersen Zari, M., 2018. Regenerative Urban Design and Ecosystem Biomimicry. Routledge, Oxon.

Pedersen Zari, M., Blaschke, P.M., Livesey, C., Martinez-Almoyna Gual, C., Weaver, S., Archie, K.M., Renwick, J., 2017. Ecosystem-based Adaptation (EbA) Project Implementation Plans, Port Vila, Vanuatu. SPREP, Wellington, New Zealand.

Potschin, M., Haines-Young, R., Fish, R., Turner, K., 2016. Ecosystem services in the twenty-first century. In: Routledge Handbook of Ecosystem Services. Routledge, pp. 1-9.

Power, S., Delage, F., Chung, C., Kociuba, G., Keay, K., 2013. Robust twenty-first-century projections of El Niño and related precipitation variability. Nature 502, 541-545.

Quantin, P., 1971. Archipel des Nouvelles Hebrides: carte pedologique de reconnaissance, Vaté. ORSTOM Office de la recherche scientifique et technique outre mer. Bondy, France. (Map). https://www.worldcat.org/title/archipel-des-nouvell es-hebrides-carte-pedologique-de-reconnaissance-vate/oclc/5481964.

Quantin, P., 1975. Soils of the new hebrides islands. Philos. Trans. R. Soc. Lond. B Biol. Sci. 272 (918), 287-292.

Rockstrom, J., Steffen, W., Noone, K., Persson, A., Chapin, F.S., Lambin, E.F., Foley, J.A., 2009. A safe operating space for humanity. Nature 461 (7263), 472-475.

Roth, A., Mercier, A., Lepers, C., Hoy, D., Duituturaga, S., Benyon, E., et al., 2014. Concurrent outbreaks of dengue, chikungunya and Zika virus infections-an unprecedented epidemic wave of mosquito-borne viruses in the Pacific 2012-2014. Euro Surveill. 19 (41), 20929.

Schomaker, M., 1997. Development of environmental indicators in UNEP. In: Paper Presented at the Land Quality Indicators and Their Use in Sustainable Agriculture and Rural Development. FAO, Rome, pp. 35-36. January 25-26, 1996.

Schwetter, M., 2012. Vanuatu Vegetation Map. Vanuatu Forestry Department. Republic of Vanuatu, Port Vila.

Secretariat of the Pacific Regional Environment Programme (SPREP), 2013. State of Conservation in Vanuatu. Vanuatu Country Report.

Sharps, K., Masante, D., Thomas, A., Jackson, B.M., Redhead, J., May, L., Prosser, H., Cosby, B., Emmett, B., Jones, L., 2017. Comparing strengths and weaknesses of three ecosystem services modelling tools in a diverse UK river catchment. Sci. Total Environ. v584-585, pp118-130.

Smeets, E., Weterings, R., 1999. Environmental Indicators: Typology and Overview. European Environment Agency, Copenhagen.

SPREP, 2018a. Pacific Ecosystem-Based Adaptation to Climate Change. Retrieved from. https://www.sprep.org/project/pacific-ecosystem-based-adaptation-climate-cha nge. (Accessed June 2019).

SPREP, 2018b. Planning for Ecosystem-Based Adaptation in Port Vila, Vanuatu. A Synthesis Report by the Secretariat of the Pacific Regional Environment Programme. Apia, Samoa. 16 pp. Retrieved from: https://www.sprep.org/sites/default/files/do cuments/publications/eba-port-vila-vanuatu.pdf. (Accessed October 2019).

Thorne, C.R., Zevenbergen, L.W., 1990. Prediction of ephemeral gully erosion on cropland in the south-eastern United States. In: Soil Erosion on Agricultural Land. Proceedings of a Workshop Sponsored by the British Geomorphological Research Group. John Wiley \& Sons Ltd, Coventry, UK, pp. 447-470. January 1989.

Trodahl, M.I., Jackson, B.M., Deslippe, J., Metherell, A.K., 2017. Investigating trade-offs between water quality and agricultural productivity using the land utilisation and capability indicator (LUCI) - a New Zealand application. Ecosyst. Serv. 26, 388-399.

Trundle, A., McEvoy, D., 2015. Port Vila Climate Vulnerability Assessment - Abridged Report. (Pre TC Pam Report and Statistics). UN Habitat and RMIT University.

Turner, R., Daily, G., 2008. The ecosystem services framework and natural capital conservation. Environ. Resour. Econ. 39 (1), 25-35.

Uthicke, S., Logan, M., Liddy, M., Francis, D., Hardy, N., Lamare, M., 2015. Climate change as an unexpected co-factor promoting coral eating seastar (Acanthaster planci) outbreaks. Sci. Rep. 5, 8402.

Wang, L., Yu, J.-Y., Paek, H., 2017. Enhanced biennial variability in the Pacific due to Atlantic capacitor effect. Nature Communications 8, 1-7. https://doi.org/10.1038/ ncomms14887, 14887.

Westoby, P., Brown, M.A., 2007. Peaceful community development in Vanuatu: a reflection on the Vanuatu Kastom governance partnership. J. Peacebuilding Dev. 3 (3), 77-81. https://doi.org/10.1080/15423166.2007.390449351269.

Wise, R.M., Fazey, I., Stafford Smith, M., Park, S.E., Eakin, H.C., Archer Van Garderen, E. R.M., Campbell, B., 2014. Reconceptualising adaptation to climate change as part of pathways of change and response. Glob. Environ. Chang. 28, 325-336. 